\title{
BIOSYNTHESIS, CHARACTERISATION AND DETERMINATION OF ADSORBENT PROPERTIES OF SILVER NANOPARTICLES WITH CYPRUS ACACIA (Acacia cyanophylla) LEAF EXTRACT
}

\author{
Fahriye TAŞKIRAN ${ }^{1}$, Deniz UZUNOĞLU ${ }^{1, *}$, Ayla ÖZER ${ }^{1}$ \\ ${ }^{1}$ Department of Chemical Engineering, Faculty of Engineering, Mersin University, Mersin, 33343, Turkey
}

\begin{abstract}
In this work, silver nanoparticles (AgNPs) were biosynthesized using Cyprus acacia (Acacia cyanophylla) leaf extract as reductant agent; the biosynthesized AgNPs were characterized by DLS, FT-IR, SEM, EDX, and XRD. Then, the single and multistage batch adsorption of Basic Red 46 dye (BR46) onto AgNPs were studied and the optimum conditions were determined as follows: initial $\mathrm{pH}$ of 7.0 , initial dye concentration of $200 \mathrm{mg} / \mathrm{L}$, temperature of $35{ }^{\circ} \mathrm{C}$, and adsorbent concentration of $1.0 \mathrm{~g} / \mathrm{L}$. For BR 46-AgNPs adsorption, the equilibrium was defined by Langmuir isotherm model and the adsorption kinetic data were best described by the pseudo second order kinetic model. From Weber-Morris model, it was concluded that only intraparticle mass transfer was effective on the adsorption of BR 46 by AgNPs. It was obtained from the thermodynamic studies that the studied adsorption system was exothermic, induced, and decreasing in randomness of adsorbed species.
\end{abstract}

Keywords: Adsorption, Biosynthesis, Cyprus acacia, Multi-stage adsorption, Silver nanoparticles

\section{INTRODUCTION}

Nanoparticles have some outstanding physicochemical properties like good electrical and thermal conductivity, high aspect ratio of ordered structure, light weight, metallic/semi-metallic feature, high mechanical endurance, large specific surface area [1]. Beginning by Faraday's study with colloidal gold in the middle of the 1800s, the unusual physicochemical properties of metallic nanoparticles have been subjects to ongoing investigation by physics and chemistry communities [2]. Metallic nanoparticles are conventionally synthesized by electro-chemical method, reverse micelles/microemulsion method, hydrothermal synthesis, sonochemical reduction, and chemical reduction [3]. Because of these methods' disadvantages such as use of hazardous chemicals and toxic materials, low conversion, difficult and costly purification requirements, high energy demand, biosynthesis methods using biological reductant agents like microorganisms, enzymes, plant extracts have attracted much attention in the recent years. The metallic nanoparticles are biosynthesized by reduction from the metal salt with the aid of the biological agents. Compared to other biological agents used in the biosynthesis method, using plant extract is more advantageous choice because plants are too available in the environment, the method does not require to sterilization, processing of plants is easier and safer. Given the diversity of plants in our country; plant leaves, unused ecofriendly resources, can be converted into economic value when they are evaluated in metallic nanoparticles biosynthesis. [4]. Recently, the metallic nanoparticles are commonly used as adsorbents in pollutant removal processes because they have remarkable advantages like only a bit of nanoparticle is sufficient for wastewater treatment, they have large specific surface area and a great number of unsaturated atoms on their surfaces resulting in comparatively high adsorption capacities [1]. In this work, the silver nanoparticles (AgNPs) were biosynthesized by using Cyprus acacia (Acacia cyanophylla) leaf extract and were characterized, and the adsorbent properties of AgNPs for BR46 dye were also determined. 


\section{MATERIALS AND METHODS}

\subsection{Biosynthesis of AgNPs}

$5.0 \mathrm{~g}$ of the purified and dried A. cyanophylla leaves were boiled in $100 \mathrm{~mL}$ of pure water at $100{ }^{\circ} \mathrm{C}$ for desired time and the leaf extract was obtained by this way. $5 \mathrm{~mL}$ of the leaf extract was added dropwise to $100 \mathrm{~mL}$ of $10^{-3} \mathrm{M} \mathrm{AgNO}_{3}$, which was stirring magnetically, and then the mixture in the conical flask was stirred magnetically for $120 \mathrm{~min}$. The resulting mixture left at room temperature for 1 day in an attempt to be accomplished the biosynthesis. By this way, +1 valent silver ion in $\mathrm{AgNO}_{3}$ structure was reduced to zero valent silver, silver nanoparticles, with the aid of the leaf extract, biological reductant agent. AgNPs precipitated at the bottom of the conical flask; and then the precipitate was separated manually from the AgNPs-leaf extract mixture. The residual AgNPs-leaf extract suspension was added to petri plates and the aqueous leaf extract was evaporated at $110{ }^{\circ} \mathrm{C}$ in the stove for $6 \mathrm{~h}$. The obtained AgNPs were washed with pure water; they were dried at $180{ }^{\circ} \mathrm{C}$ in the stove for $24 \mathrm{~h}$, and were stored at $+4{ }^{\circ} \mathrm{C}$ in the refrigerator [5]. The characterization studies of the biosynthesized AgNPs were carried out by Fourier Transform Infrared Spectrometer (FTIR- Perkin Elmer, Shelton), Scanning Electron Microscope (SEM- Zeiss/Supra 55, Germany), Energy Dispersive X-ray Spectroscopy (EDX- Zeiss/Supra 55, Germany), X-ray Diffractometer (XRD- Philips XPert, Netherlands), zetasizer (Malvern, UK) using Dynamic Light Scattering (DLS) technique, and zetapotential analyzer (Malvern, UK).

\subsection{Adsorption Studies}

Adsorption studies were done with artificial wastewater containing BR46 (molecular formula: $\mathrm{C}_{18} \mathrm{H}_{21} \mathrm{BrN}_{6}$, CAS Registry Number:12221-69-1, molar mass: $401.3 \mathrm{~g} / \mathrm{g}-\mathrm{mole}$ ). In this work, the effects of experimental conditions such as initial $\mathrm{pH}(7.0,8.0,9.0$, and 10), initial dye concentration $(25,50,75,100,150,200,300$, and $500 \mathrm{mg} / \mathrm{L})$, temperature $\left(25,35,45\right.$, and $\left.55^{\circ} \mathrm{C}\right)$, and adsorbent concentration $(0.5,1.0,2.0$, and $3.0 \mathrm{~g} / \mathrm{L})$ were investigated in a batch system. $\quad 0.1 \mathrm{~g}$ of the synthesized AgNPs (not suspension of AgNPs) were added to $100 \mathrm{~mL}(0.1 \mathrm{~L})$ of dye solution, equal to $(0.1 \mathrm{~g}$ adsorbent $) /(0.1 \mathrm{~L}$ dye solution $)=1.0 \mathrm{~g} / \mathrm{L}$ of adsorbent concentration, for the all adsorption studies except for the adsorbent concentration experiments. The other adsorbent concentrations can be calculated in the same way. In this respect, the required amount of AgNPs was blended with $100 \mathrm{~mL}$ of the dye solution in 250-mL conical flasks. In order to achieve the adsorption equilibrium, the flasks were shaken in a thermostated water bath at constant temperature for $180 \mathrm{~min}$. At predetermined time intervals $(0.0,0.5,2.0,5.0,10,20,30,60,120$, and $180 \mathrm{~min})$, the sample of dye solution was taken and separated from the adsorbent with centrifuge at $3000 \mathrm{rev} / \mathrm{min}$ for $5.0 \mathrm{~min}$. The residual dye concentration in the supernatant was analyzed at $530 \mathrm{~nm}$ by UV-vis spectrophotometer (Chebios Optimum-One, Italy).

The adsorbed amount at equilibrium, $\mathrm{q}_{\mathrm{eq}}(\mathrm{mg} / \mathrm{g})$, and the percentage of adsorption (\%) were computed as follows:

$$
\begin{aligned}
\mathrm{q}_{\mathrm{eq}} & =\frac{\mathrm{C}_{\text {init }}-\mathrm{C}_{\mathrm{eq}}}{\mathrm{X}_{\text {init }}} \\
& \text { Percent adsorption }(\%)=\frac{\mathrm{C}_{\text {init }}-\mathrm{C}_{\mathrm{eq}}}{\mathrm{C}_{\text {init }}} \times 100
\end{aligned}
$$

\section{RESULTS AND DISCUSSION}

\subsection{Adsorbent Characterization}

The distribution of effective hydrodynamic diameters of biosynthesized AgNPs was measured by DLS technique and the results were presented in Figure 1. As can be seen from Figure 1, single AgNPs with 
the effective hydrodynamic diameter of $32.67 \mathrm{~nm}$ were the most frequent ones $(14.20 \%)$ while the smallest AgNPs $(15.69 \mathrm{~nm})$ had the distribution of $3.50 \%$ and the average particle size of the biosynthesized AgNPs was determined as $38.55 \mathrm{~nm}$ with low polydispersity index (PDI) of 0.246 by DLS technique.

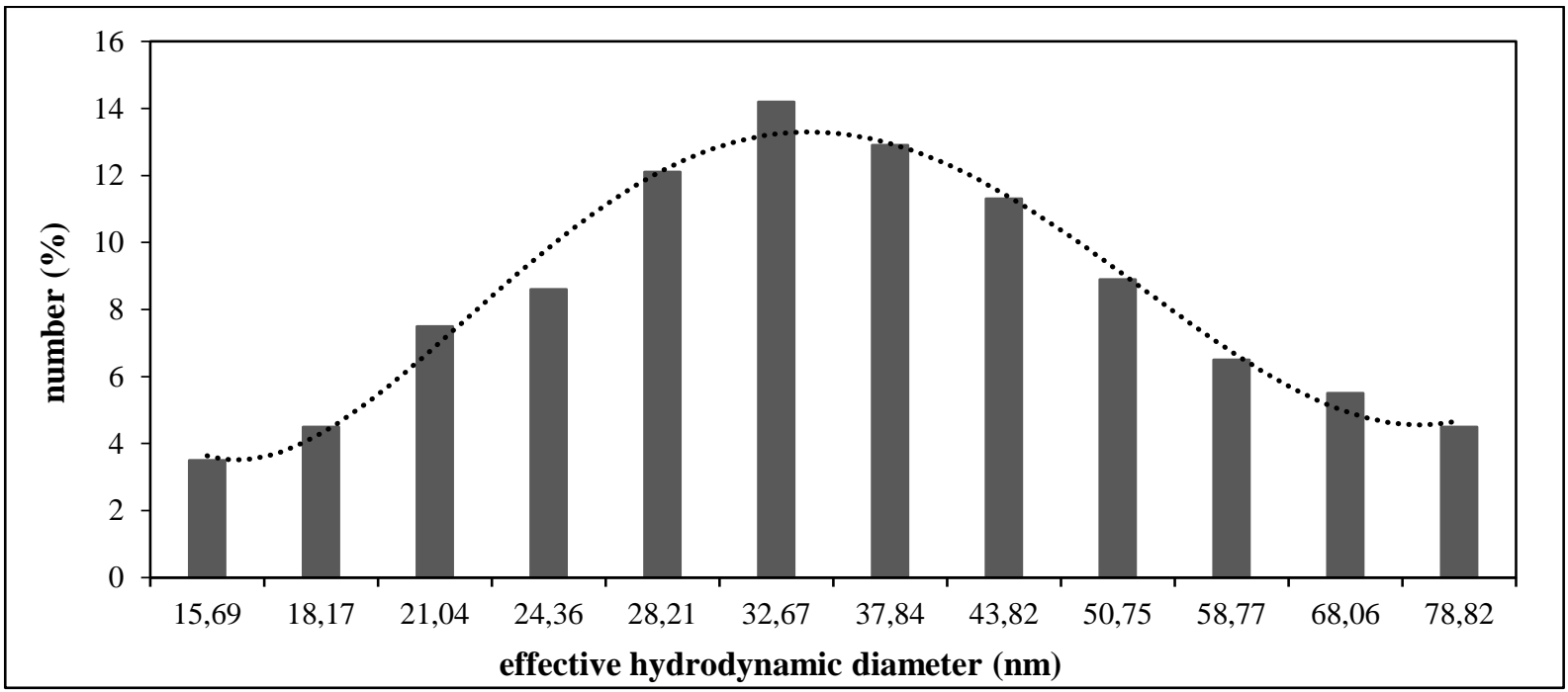

Figure 1. The distribution of effective hydrodynamic diameters of AgNPs

FT-IR spectra of AgNPs before and after the adsorption were given in Figure 2. Accordingly; $=\mathrm{C}-\mathrm{H}$ alkenes $\left(2980 \mathrm{~cm}^{-1}\right),-\mathrm{C}-\mathrm{H}$ alkanes $\left(2887 \mathrm{~cm}^{-1}\right),-\mathrm{COOH}$ carbonyl group $\left(1630 \mathrm{~cm}^{-1}\right), \mathrm{C}=\mathrm{C}$ aromatic group $\left(1410 \mathrm{~cm}^{-1}\right),-\mathrm{C}-\mathrm{H}$ alkane $\left(1387 \mathrm{~cm}^{-1}\right), \mathrm{C}-\mathrm{N}$ stretch aliphatic amines $\left(1091 \mathrm{~cm}^{-1}\right), \mathrm{C}-\mathrm{N}$ amines $\left(1005 \mathrm{~cm}^{-1}\right), \mathrm{C}-\mathrm{H}$ oop aromatics $\left(818 \mathrm{~cm}^{-1}\right.$ to $\left.660 \mathrm{~cm}^{-1}\right)$ peaks were observed from FT-IR spectra of AgNPs [6].

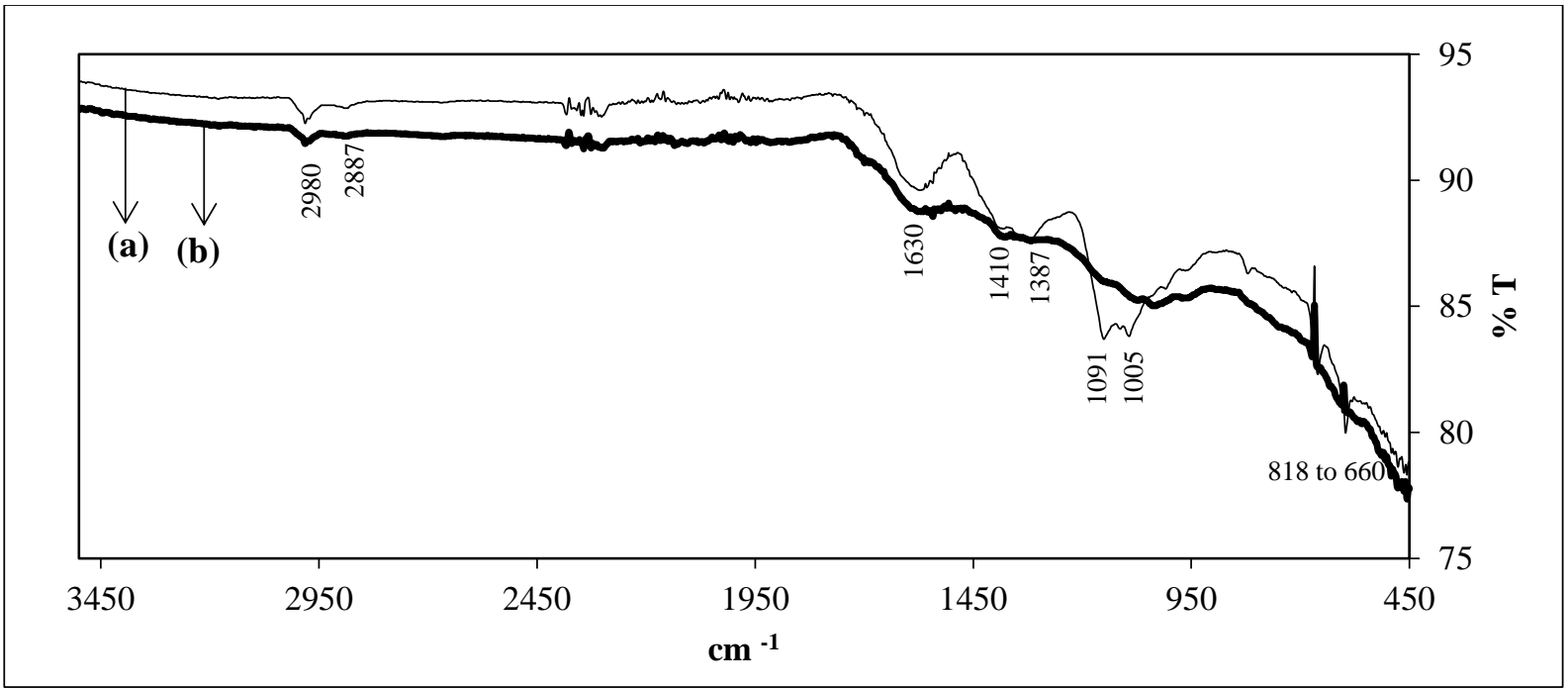

Figure 2. (a) FT-IR spectrum of AgNPs before adsorption; (b) FT-IR spectrum of AgNPs after adsorption

According to Figure 2. (b); the peaks of 1091 and $1005 \mathrm{~cm}^{-1}$ were disappeared post-adsorption, which indicating that amines were responsible groups in the adsorption. 
XRD patterns of AgNPs before and after the adsorption were given in Figure 3. XRD pattern of AgNPs exhibited peaks at $2 \theta$ angles of $38.10^{\circ}, 44.28^{\circ}, 64.41^{\circ}$, and $77.36^{\circ}$ which corresponded to the

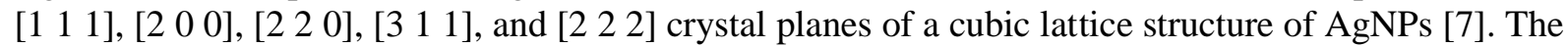
unassigned peaks were also observed indicating the crystallization of bio-organic phase on the surface of the silver nanoparticles due to the leaf extract [8]. The obtained XRD patterns were consistent with the various similar studies in the literature [5, 9-12].

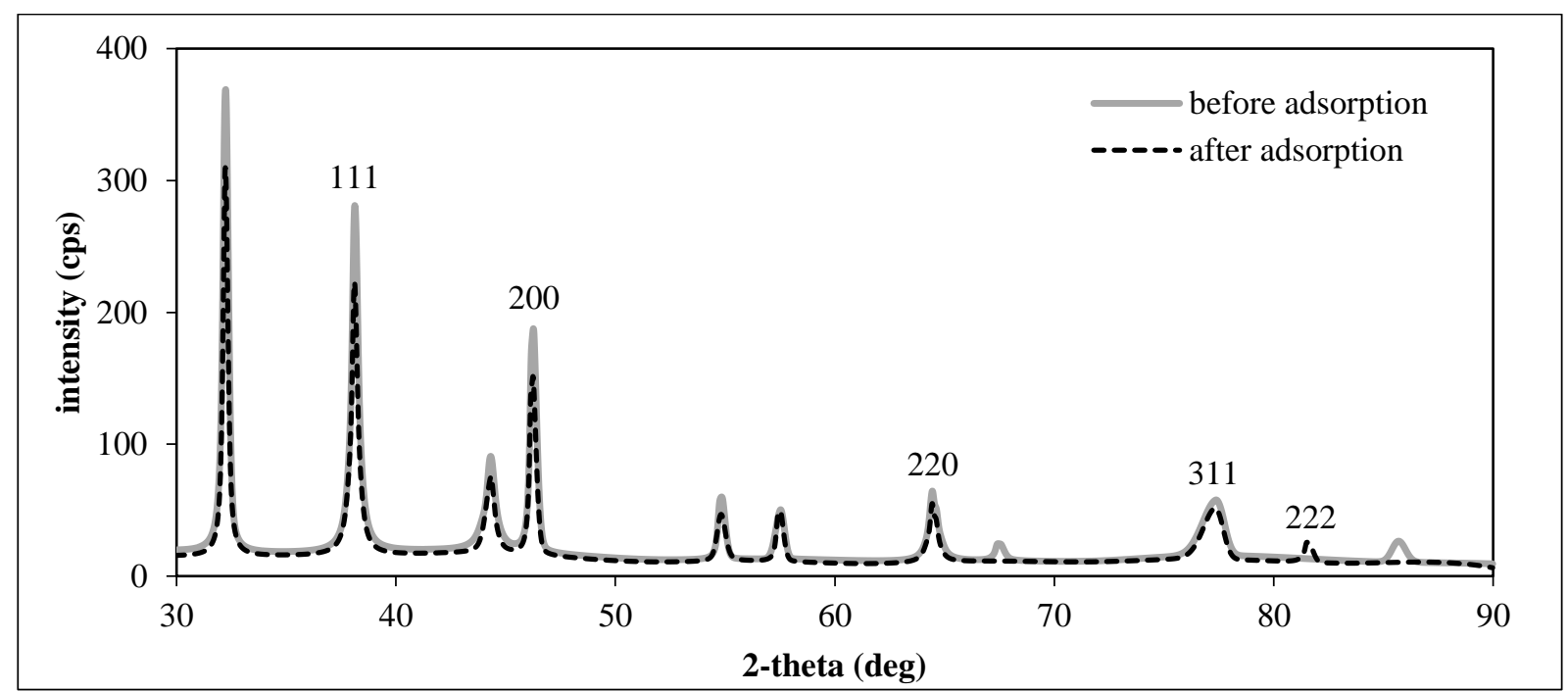

Figure 3. XRD patterns of AgNPs

Moreover, there was not any difference between before and after adsorption for XRD patterns of AgNPs, which was indicating the phenomena of physical adsorption.

EDX analysis results were given in Table 1 and it showed that AgNPs involved $90.43 \%$ Ag, $3.99 \%$ $\mathrm{Cl}, 3.18 \% \mathrm{C}$, and $2.40 \% \mathrm{O}$ before adsorption. Accordingly, the strong signal in the silver region affirmed the formation of AgNPs, the obtained of carbon, oxygen, and nitrogen elements stemmed from the extracellular organic moieties of A. cyanophylla extract on the adsorbent surface. The observed $0.76 \% \mathrm{~N}$ and the increase in weight percentages of $\mathrm{C}$ and $\mathrm{O}$ post-adsorption resulted from the adsorbed $\mathrm{BR} 46\left(\mathrm{C}_{18} \mathrm{H}_{21} \mathrm{BrN}_{6}\right)$ molecules onto AgNPs.

Table 1. EDX analysis results

\begin{tabular}{ccc}
\hline \multirow{2}{*}{ Element } & \multicolumn{3}{c}{ Weight \% } \\
\cline { 2 - 3 } & Pre-adsorption & Post-adsorption \\
\hline Ag & 90.43 & 90.35 \\
$\mathbf{C}$ & 3.18 & 3.23 \\
$\mathbf{O}$ & 2.40 & 2.42 \\
$\mathbf{C l}$ & 3.99 & 3.24 \\
$\mathbf{N}$ & - & 0.76 \\
\hline
\end{tabular}

From SEM images (Figure 4), the porous structures were observed pre-adsorption (a) and these pores were covered by BR46 molecules post-adsorption (b). 


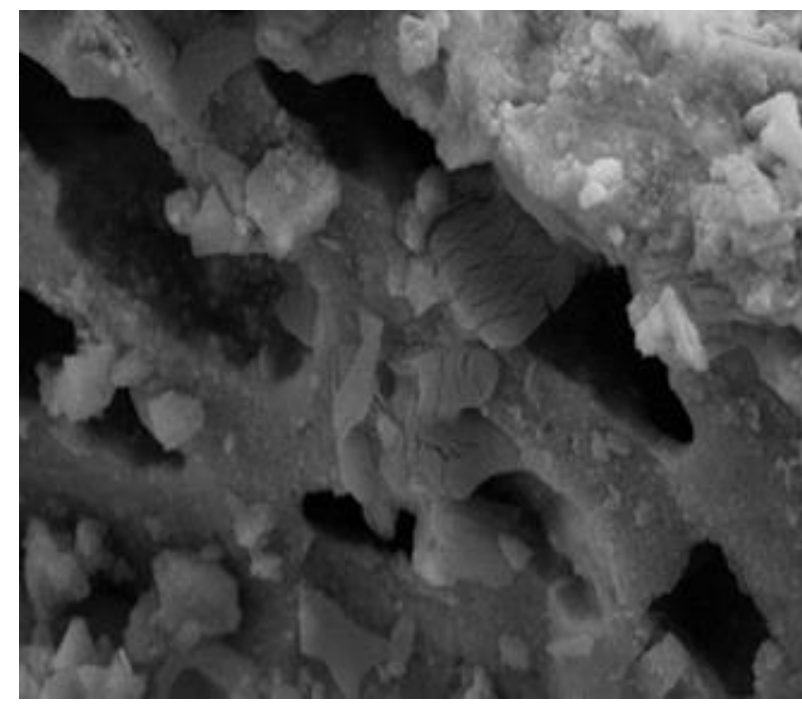

(a)

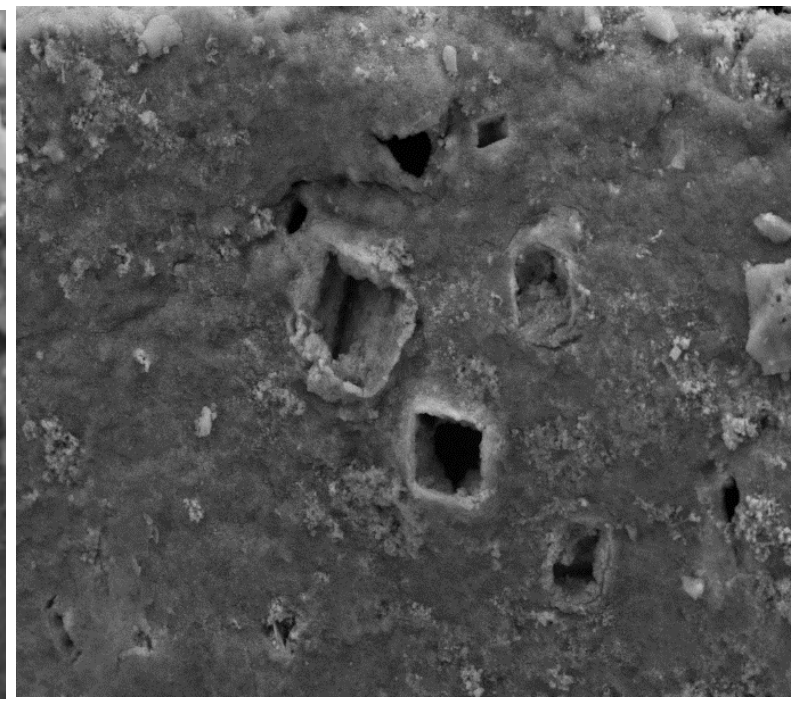

(b)

Figure 4. (a) SEM images of AgNPs before adsorption; (b) SEM images of AgNPs after adsorption

\subsection{The Single and Multi-Stage Adsorption of Basic Red 46 onto AgNPs}

The single stage adsorption of BR46 onto AgNPs was investigated in a batch process for various experimental conditions such as initial $\mathrm{pH}$, initial dye concentration, temperature, and adsorbent concentration.

\subsubsection{Effects of initial pH}

The effect of initial $\mathrm{pH}$ on $\mathrm{BR} 46$ adsorption was studied in the range of $7.0-10$ at $25^{\circ} \mathrm{C}$ temperature, $1.0 \mathrm{~g} / \mathrm{L} \mathrm{AgNPs}$ concentration, and $100 \mathrm{mg} / \mathrm{L}$ initial BR46 concentration for $180 \mathrm{~min}$ contact time and the equilibrium uptake amounts at different initial $\mathrm{pH}$ values were presented in Figure 5.a. From 5.a, it was observed that the maximum equilibrium BR 46 uptake amount $\left(\mathrm{q}_{\mathrm{eq}}\right)$ was observed at initial $\mathrm{pH} 7.0$ and $\mathrm{q}_{\mathrm{eq}}$ values decreased with increasing initial $\mathrm{pH}$ thereafter. This state can be explained by the zeta potential analysis for AgNPs (Figure 5.b). It is well-known that a suspension with zeta potential above $\pm 30 \mathrm{mV}$ is stable and above $\pm 60 \mathrm{mV}$ shows excellent stability while a suspension with zeta potential below $\pm 20 \mathrm{mV}$ has limited stability and below $\pm 5 \mathrm{mV}$ aggregates significantly [13]. Accordingly, the surface of AgNPs had the maximum negative charge $(-24.17 \mathrm{mV})$ at $\mathrm{pH} 7.0$; therefore, in consequence of the strong electrostatic attraction between the anionic adsorbent surface and BR46 cations, the maximum adsorbed BR46 amount was observed at this $\mathrm{pH}$ value. The negative charge of AgNPs surface decreased at higher $\mathrm{pH}$ values than 7.0 and so the adsorbed amounts also decreased thereafter as a result of the decreasing in the mentioned electrostatic attraction. For these reasons, the optimum initial $\mathrm{pH}$ was determined as 7.0 for BR 46 adsorption onto AgNPs. 
Taşkıran et al. /Anadolu Univ. J. of Sci. and Technology A-Appl. Sci. and Eng. 18 (3) - 2017

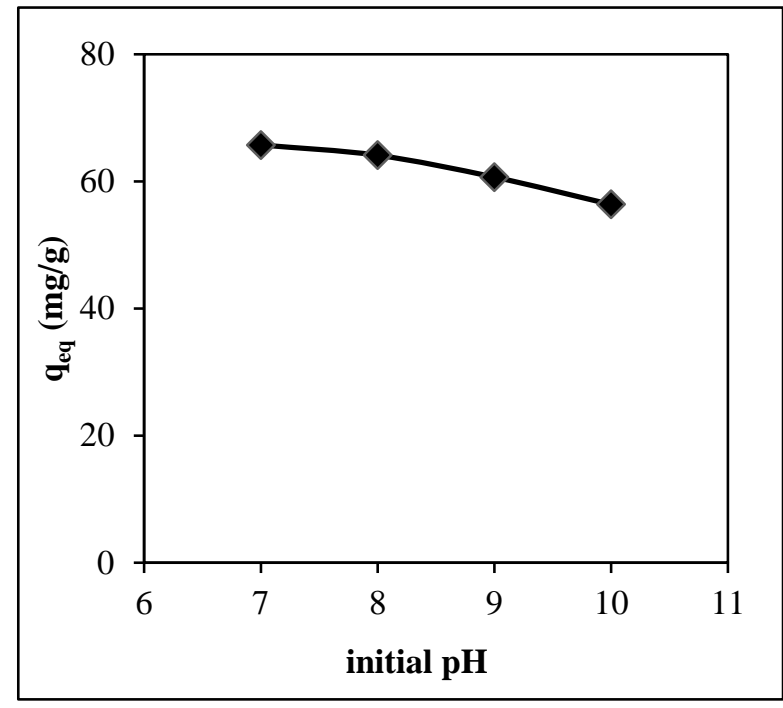

(a)

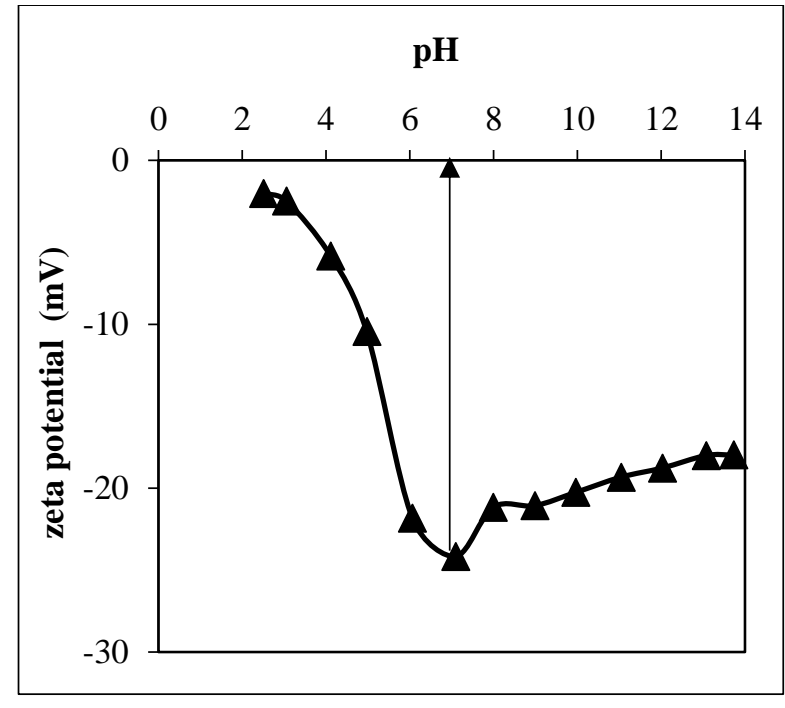

(b)

Figure 5. (a) Initial $\mathrm{pH}$ effect; (b) zeta potential values of AgNPs for different $\mathrm{pHs}$

\subsubsection{Effects of temperature}

The studies of temperature effects on BR46 adsorption onto AgNPs was done in the range of $25-55{ }^{\circ} \mathrm{C}$ at $100 \mathrm{mg} / \mathrm{L}$ initial BR46 concentration, 7.0 initial $\mathrm{pH}$, and $1.0 \mathrm{~g} / \mathrm{L} \mathrm{AgNPs}$ concentration for $180 \mathrm{~min}$ contact time and the equilibrium uptake amounts at different temperatures were presented in Figure 6.

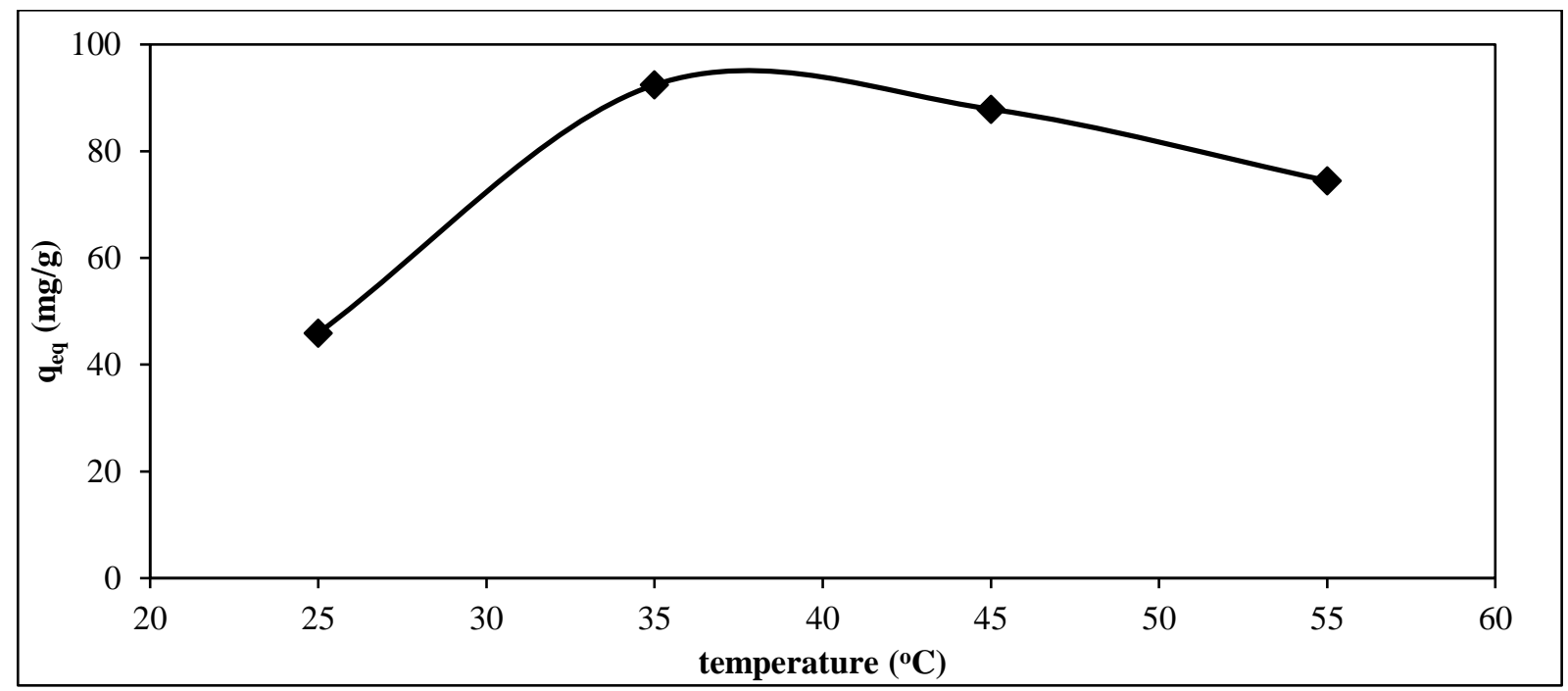

Figure 6. Temperature effect

As can be seen from Figure 6, $\mathrm{q}_{\mathrm{eq}}$ values increased with increase in temperature down to $35^{\circ} \mathrm{C}$ and then they decreased hereafter. The increasing of $\mathrm{q}_{\mathrm{eq}}$ values with temperature can be explained the opening of the pores in the adsorbent surface in the range of $25-35^{\circ} \mathrm{C}$. The decrease of qeq values with further increase in temperature arose from the physical and exothermic phenomena of BR46 adsorption on AgNPs. Therefore, the optimum temperature value was found as $35{ }^{\circ} \mathrm{C}$ for $\mathrm{BR} 46$ adsorption onto AgNPs. 
To evaluate the effect of temperature on BR46 adsorption onto AgNPs in details, the thermodynamic parameters of change of Gibb's energy $(\Delta \mathrm{G})$, change of enthalpy $(\Delta \mathrm{H})$, and change of entropy $(\Delta \mathrm{S})$ were determined with Van't Hoff equation and the calculated parameters were given in Table 2. Table 2 showed that BR46 adsorption onto AgNPs was exothermic $(\Delta \mathrm{H}<0)$, induced $(\Delta \mathrm{G}>0)$, and decreasing in randomness of adsorbed species $(\Delta \mathrm{S}<0)$.

Table 2. Thermodynamic parameters

\begin{tabular}{cccc}
\hline $\mathbf{T}\left({ }^{\mathbf{0}} \mathbf{C}\right)$ & $\boldsymbol{\Delta G}(\mathbf{J} / \mathbf{m o l e})$ & $\Delta \mathbf{H}(\mathbf{J} / \mathbf{m o l e})$ & $\Delta \mathbf{S ~ ( J / m o l e . K})$ \\
\hline 35 & 2829 & & -72.47 \\
45 & 3477 & -19518 & \\
55 & 4281 & & \\
\hline
\end{tabular}

In order to discuss the effect of the temperature on the adsorption equilibrium in details, the linear forms of Langmuir $\left(\frac{1}{\mathrm{q}_{\mathrm{eq}}}=\frac{1}{\mathrm{q}_{\mathrm{m}} \cdot \mathrm{b}_{\mathrm{L}} \cdot \mathrm{C}_{\mathrm{eq}}}+\frac{1}{\mathrm{q}_{\mathrm{m}}}\right)$ and Freundlich $\left(\ln \left(\mathrm{q}_{\mathrm{eq}}\right)=\ln \left(\mathrm{K}_{\mathrm{fr}}\right)+\frac{1}{\mathrm{n}} \frac{1}{\mathrm{C}_{\mathrm{eq}}}\right)$ adsorption isotherm models were evaluated for different temperature values and the obtained isotherm constants along with the regression coefficients $\left(\mathrm{R}^{2}\right)$ and error values ( $\left.\operatorname{Err}=\left(\frac{100}{\mathrm{n}}\right) \sum_{1}^{\mathrm{n}}\left|\frac{\left(\mathrm{q}_{\text {eq,cal }}-\mathrm{q}_{\mathrm{eq}, \mathrm{ex}}\right.}{\mathrm{q}_{\mathrm{eq}, \mathrm{ex}}}\right|\right)$ ) were presented in Table 3. Accordingly, higher regression coefficients $\left(\mathrm{R}^{2}>0.99\right)$ and lower Err values of Langmuir isotherm model showed that BR46 adsorption equilibrium data best described by Langmuir isotherm model indicating that BR46 adsorption onto AgNPs was monolayer in nature. Besides, it was noted that the maximum monolayer adsorption capacity was determined at $35{ }^{\circ} \mathrm{C}$, which was the optimum temperature value for BR46 adsorption onto AgNPs.

Table 3. Isotherm constants and the related regression coefficients $\left(\mathrm{R}^{2}\right)$ for the adsorption of BR46 onto AgNPs at various temperatures

\begin{tabular}{ccccccccc}
\hline \multirow{2}{*}{$\mathbf{T}$} & \multicolumn{3}{c}{ Langmuir isotherm model } & \multicolumn{4}{c}{ Freundlich isotherm model } \\
\cline { 2 - 9 }$\left({ }^{\mathbf{C}} \mathbf{C}\right)$ & $\begin{array}{c}\mathbf{q} \mathbf{m} \\
(\mathbf{m g} / \mathbf{g})\end{array}$ & $\begin{array}{c}\mathbf{b}_{\mathbf{L}} \\
(\mathbf{L} / \mathbf{m g})\end{array}$ & $\mathbf{E r r}$ & $\mathbf{R}^{\mathbf{2}}$ & $\begin{array}{c}\mathbf{K}_{\mathbf{f r}} \\
\left.(\mathbf{m g} / \mathbf{g})(\mathbf{L} / \mathbf{m g}))^{\mathbf{1} \mathbf{n}}\right)\end{array}$ & $\mathbf{1 / n}$ & $\mathbf{E r r}$ & $\mathbf{R}^{\mathbf{2}}$ \\
\hline 25 & 98.97 & 0.0124 & 7.12 & 0.995 & 4.27 & 0.526 & 10.41 & 0.956 \\
35 & 126.48 & 0.1473 & 3.74 & 0.994 & 31.85 & 0.266 & 19.24 & 0.834 \\
45 & 115.27 & 0.0990 & 5.18 & 0.994 & 26.63 & 0.277 & 19.81 & 0.796 \\
55 & 89.81 & 0.1800 & 4.86 & 0.993 & 29.22 & 0.214 & 17.94 & 0.761 \\
\hline
\end{tabular}

The adsorption mechanism of BR 46 on AgNPs progresses in accordance with the assumptions of the Langmuir isotherm model. The prevenient mechanism of BR46 adsorption onto AgNPs as follows;

$$
\mathrm{COO}^{-}+\left[\mathrm{C}_{18} \mathrm{H}_{21} \mathrm{~N}_{6}\right]^{+} \rightarrow\left[\left(\mathrm{COO}^{-}\right)\left(\mathrm{C}_{18} \mathrm{H}_{21} \mathrm{~N}_{6}\right)^{+}\right]
$$

According to Eq. 3, one cationic BR46 molecule $\left(\left[\mathrm{C}_{18} \mathrm{H}_{21} \mathrm{~N}_{6}\right]^{+}\right)$could adsorb onto carboxyl groups $\left(\mathrm{COO}^{-}\right)$of AgNPs surface (indicated by FT-IR) and further adsorption cannot occur at that site on the adsorbent surface.

Also, Table 4 represented the maximum adsorption capacities of AgNPs for different dyes in the literature. It was observed that AgNPs used in this work had higher adsorption capacity as against the other AgNPs used as adsorbents for different dyes in the literature. 
Taşkıran et al. /Anadolu Univ. J. of Sci. and Technology A-Appl. Sci. and Eng. 18 (3) - 2017

Table 4. The adsorption capacities of AgNPs synthesized by different methods in the literature

\begin{tabular}{|c|c|c|c|c|c|}
\hline Adsorbent & Synthesis Method & $\begin{array}{l}\text { Particle size } \\
\text { (nm) }\end{array}$ & Dye & $\begin{array}{c}\mathbf{q m} \\
(\mathbf{m g} / \mathbf{g})\end{array}$ & Reference \\
\hline AgNPs loaded & Reduction by $\mathrm{NaOH}$ & 20-90 & Direct yellow 12 & 454.54 & [1] \\
\hline $\begin{array}{l}\text { AgNPs- } \\
\text { colemanite ore }\end{array}$ & $\begin{array}{l}\text { Thermal reduction } \\
\text { without reductant }\end{array}$ & $5-30$ & $\begin{array}{l}\text { Reactive Yellow } 86 \\
\text { Reactive Red } 2\end{array}$ & $\begin{array}{l}68.71 \\
59.13\end{array}$ & [14] \\
\hline $\begin{array}{l}\text { Polyaniline/Ag } \\
\text { nanocomposite }\end{array}$ & Reduction by $\mathrm{NaOH}$ & 4.97 & Brilliant green & 23.66 & [15] \\
\hline AgNPs & $\begin{array}{l}\text { Biosynthesis by } A \text {. } \\
\text { cyanophylla extract }\end{array}$ & 103 & Basic Red 46 & 126.48 & This study \\
\hline
\end{tabular}

\subsubsection{Effects of initial dye concentration}

In order to evaluate the effect of initial dye concentration, the adsorption experiments were carried out in the range of $25-500 \mathrm{mg} / \mathrm{L}$ at $35^{\circ} \mathrm{C}$ temperature, 7.0 initial $\mathrm{pH}$, and $1.0 \mathrm{~g} / \mathrm{L} \mathrm{AgNPs}$ concentration for 180 min contact time and the equilibrium uptake amounts along with the adsorption percentages for various initial concentrations of BR46 were presented in Figure 7. According to Figure 7, qeq values increased with increase in the initial BR46 concentration down to $200 \mathrm{mg} / \mathrm{L}$ in consequence of the increasing driving force $(\Delta \mathrm{C})$ and then remained constant thereafter because at high concentrations, the available binding sites on the adsorbent become less forming the limiting factor for the adsorption. Therefore, in BR 46 adsorption onto AgNPs, the optimum initial concentration of BR46 was observed as $200 \mathrm{mg} / \mathrm{L}$.

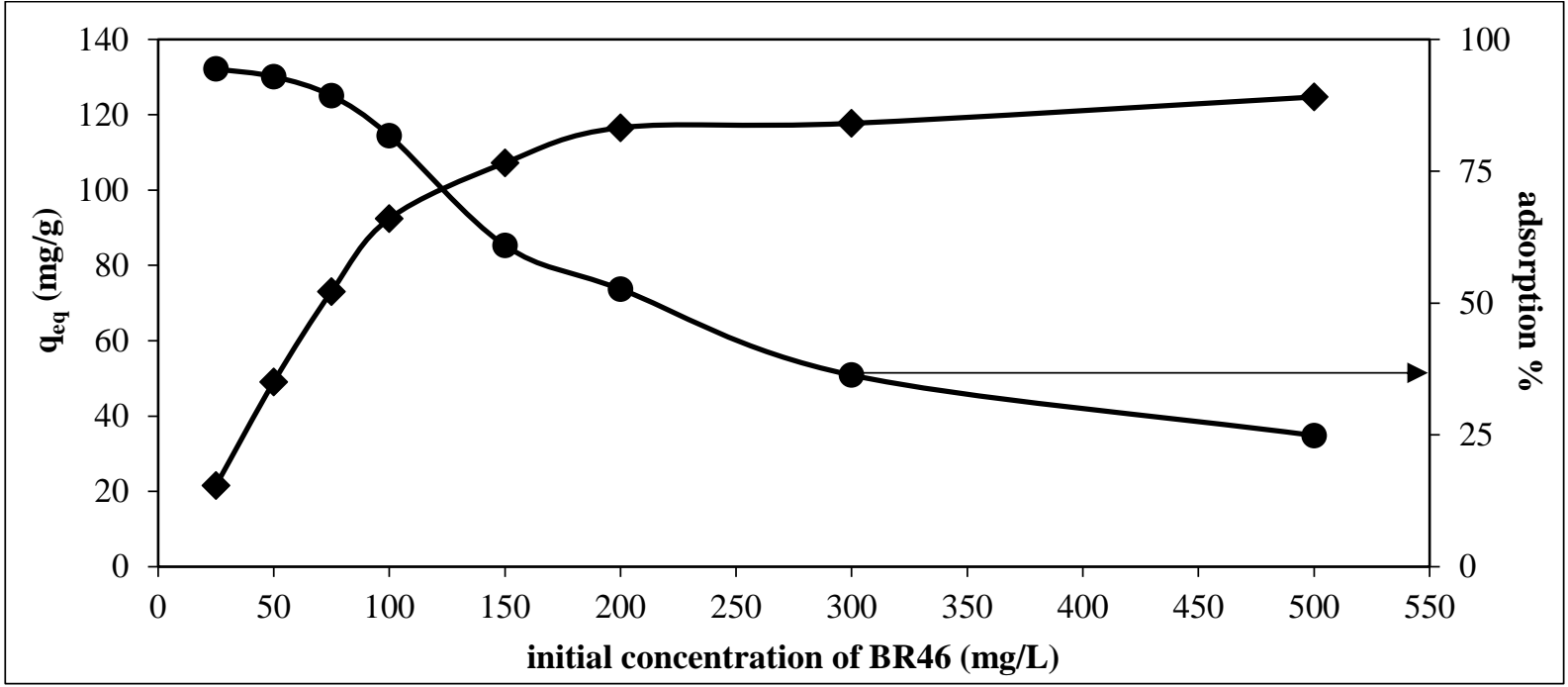

Figure 7. Initial dye concentration effect

The most important parameter affecting adsorption kinetics was the initial solute concentration. In this study, the experimental adsorption data determined at different initial BR46 concentrations were used to evaluate the kinetics of BR46 adsorption on AgNPs. The pseudo first order $\left(\log \left(\mathrm{q}_{\mathrm{eq}}-\mathrm{q}_{\mathrm{t}}\right)=\log \left(\mathrm{q}_{\mathrm{eq}}\right)-\frac{\mathrm{k}_{\mathrm{f}} \mathrm{t}}{2.303}\right)$ and the pseudo second order $\left(\frac{\mathrm{t}}{\mathrm{q}_{\mathrm{t}}}=\frac{1}{\mathrm{q}_{\mathrm{eq}}^{2} \cdot \mathrm{k}_{\mathrm{s}}}+\frac{\mathrm{t}}{\mathrm{q}_{\mathrm{eq}}}\right)$ kinetic models were applied to the experimental kinetic data for various initial BR46 concentrations, and the results were shown in Table 5. Higher values of regression coefficients and the consistency between experimental $\left(\mathrm{q}_{\mathrm{eq}, \mathrm{ex}}\right)$ and calculated $\left(\mathrm{q}_{\mathrm{eq}, \mathrm{cal} 2}\right)$ uptake values from kinetic models showed excellent fit of the pseudo second order kinetic model as seen from Table 5 . 
Taşkıran et al. /Anadolu Univ. J. of Sci. and Technology A-Appl. Sci. and Eng. 18 (3) - 2017

Table 5. Kinetic parameters and the related regression coefficients $\left(\mathrm{R}^{2}\right)$ for the adsorption of BR46 onto AgNPs at various initial concentrations

\begin{tabular}{|c|c|c|c|c|c|c|c|c|c|}
\hline \multirow{2}{*}{$\begin{array}{c}\mathrm{C}_{\text {init }} \\
(\mathrm{mg} / \mathrm{L})\end{array}$} & \multirow{2}{*}{$\begin{array}{c}\text { qeq,ex } \\
(\mathbf{m g} / \mathrm{g})\end{array}$} & \multicolumn{3}{|c|}{$\begin{array}{l}\text { Pseudo first order } \\
\text { kinetic model }\end{array}$} & \multicolumn{3}{|c|}{$\begin{array}{c}\text { Pseudo second order } \\
\text { kinetic model }\end{array}$} & \multicolumn{2}{|c|}{ Weber-Morris model } \\
\hline & & $\begin{array}{l}\text { qeq,cal1 } \\
(\mathbf{m g} / \mathrm{g})\end{array}$ & $\mathbf{k}_{\mathbf{f}}\left(\mathbf{m i n}^{-1}\right)$ & $\mathbf{R}^{2}$ & $\begin{array}{l}\text { qeq,cal2 } \\
(\mathrm{mg} / \mathrm{g})\end{array}$ & $k_{\mathrm{s}}$ (g/mg.min) & $\mathbf{R}^{2}$ & $\begin{array}{c}\mathbf{K}_{\text {in }} \\
\left(\mathrm{mg} / \mathrm{g} . \min ^{0.5}\right)\end{array}$ & $\mathbf{R}^{2}$ \\
\hline 25 & 24.35 & 17.88 & 0.0324 & 0.983 & 25.11 & 0.0061 & 0.999 & 3.766 & 0.990 \\
\hline 50 & 49.06 & 41.57 & 0.0253 & 0.988 & 51.69 & 0.0017 & 0.991 & 5.949 & 0.980 \\
\hline 75 & 73.07 & 65.87 & 0.0179 & 0.985 & 76.87 & 0.0008 & 0.995 & 6.777 & 0.990 \\
\hline 100 & 92.42 & 71.79 & 0.0244 & 0.965 & 96.03 & 0.0010 & 0.990 & 10.98 & 0.986 \\
\hline 150 & 107.22 & 88.14 & 0.0246 & 0.937 & 110.53 & 0.0008 & 0.987 & 9.295 & 0.971 \\
\hline 200 & 116.55 & 98.58 & 0.0133 & 0.965 & 117.42 & 0.0005 & 0.976 & 9.431 & 0.983 \\
\hline 300 & 117.71 & 114.26 & 0.0214 & 0.909 & 122.83 & 0.0011 & 0.997 & 14.120 & 0.980 \\
\hline
\end{tabular}

To interpret the effects of the external diffusion and intraparticle diffusion on BR46 adsorption by AgNPs, Weber-Morris model $\left(\mathrm{q}_{\mathrm{i}}=\mathrm{K}_{\mathrm{in}} \cdot \sqrt{\mathrm{t}}+\mathrm{I}\right)$ was applied to the experimental data at different initial BR 46 concentrations and the calculated parameters were presented in Table 5. According to WeberMorris model, if the plot of $\mathrm{q}_{\mathrm{t}}$ versus $\sqrt{\mathrm{t}}$ is linear and pass through the origin, the adsorption process follows only intraparticle diffusion. On the other side, the Weber-Morris plot can be linear and also has intercept value if both intraparticle and film diffusion are effective on the adsorption process. As a result, only intraparticle diffusion was effective on BR46 adsorption onto AgNPs due to the lack of intercept values of Weber-Morris plots as seen in Table 5.

\subsubsection{Effects of adsorbent concentration: modelling of multistage adsorption}

The effect of adsorbent concentration on BR 46 adsorption onto AgNPs was studied for 0.5, 1.0, 2.0, and $3.0 \mathrm{~g} / \mathrm{L}$ at 7.0 initial $\mathrm{pH}, 100 \mathrm{mg} / \mathrm{L}$ initial BR46 concentration, and $35^{\circ} \mathrm{C}$ temperature for $180 \mathrm{~min}$ contact time. The variation of the equilibrium uptake amounts and percentages of adsorption with adsorbent concentration was given in Figure 8. From Figure 8, $\mathrm{q}_{\mathrm{eq}}$ values decreased while the adsorption percentages increased with increasing the adsorbent concentration. This can be explained with the availability of more number of binding sites on the adsorbent surface for lower adsorbent concentration and particle interaction like overlapping/aggregation of adsorption sites at high adsorbent concentrations. As a result, an adsorption system containing low adsorbent concentration may be offered for the desired purification because higher $\mathrm{q}_{\mathrm{eq}}$ values were attained at low adsorbent concentrations. For these reasons, the optimum AgNPs concentration was observed as $1.0 \mathrm{~g} / \mathrm{L}$ for BR46 adsorption onto AgNPs.

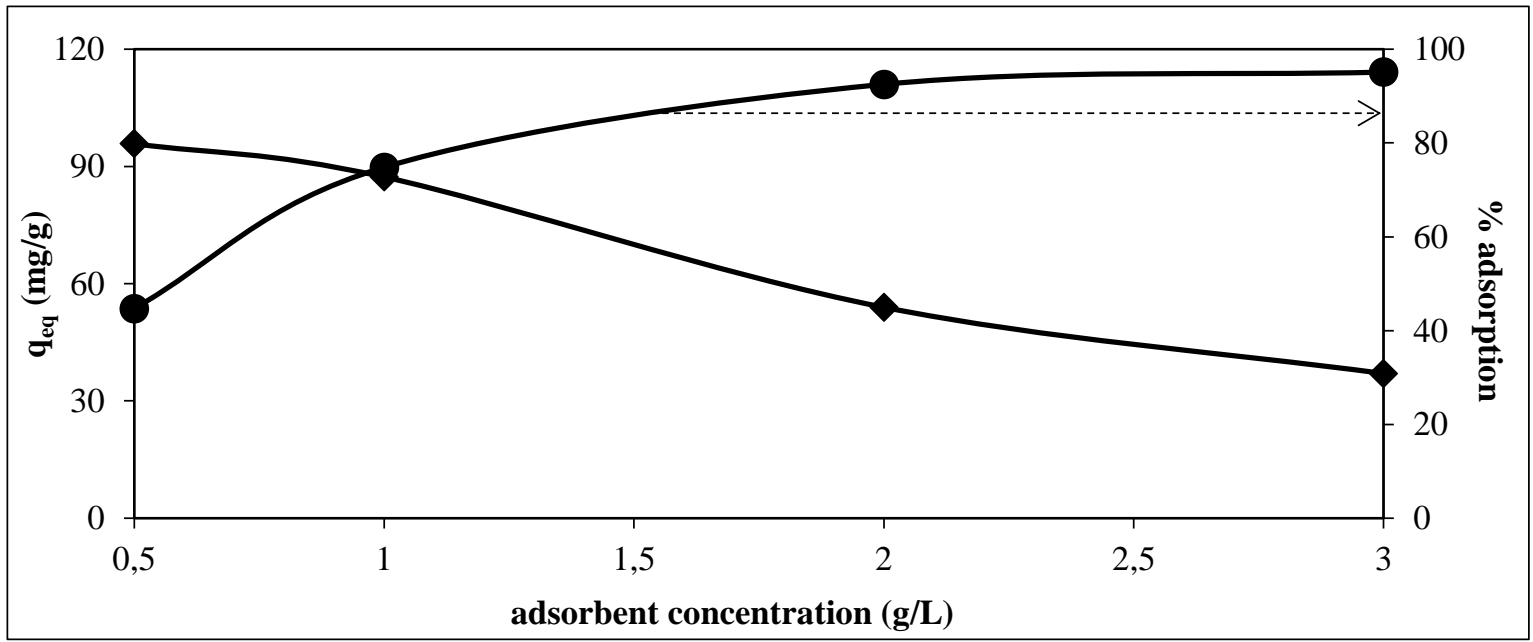

Figure 8. Adsorbent concentration effect 
If the adsorption process is separated in multistage small batches of adsorbent instead of in a single batch, with filtration between each stage, the higher removal capacity can be achieved with higher economy of adsorbent. $\mathrm{n}$-staged removal process which involved $\mathrm{V}_{\text {init }}$ volume of BR46 solution was given in Figure 9, and the mass balance of dye for $1^{\text {st }}$ stage represented in Eq. 4.

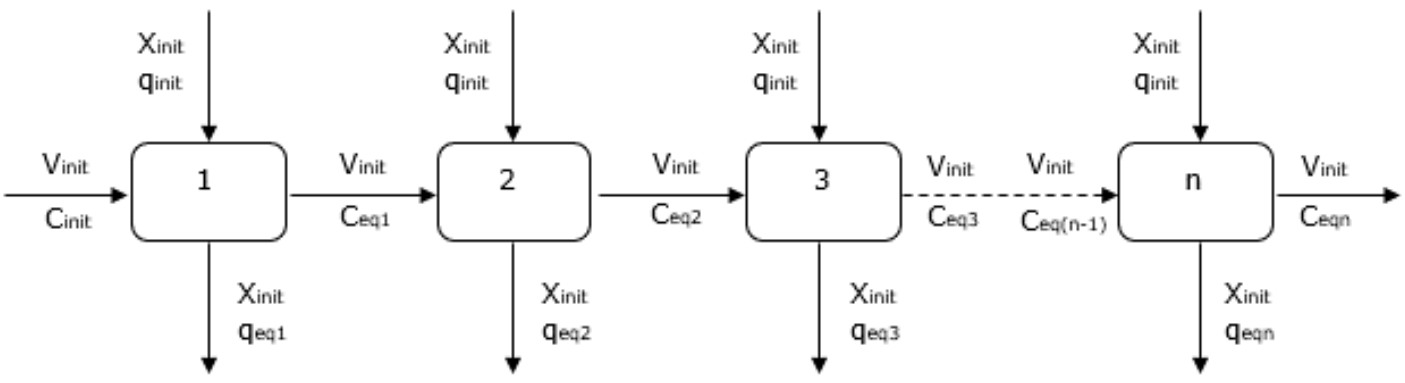

Figure 9. Multistage removal process

$$
\mathrm{V}_{\text {init }} \cdot \mathrm{C}_{\text {init }}+\mathrm{X}_{\text {init }} \cdot \mathrm{q}_{\text {init }}=\mathrm{X}_{\text {init }} \cdot \mathrm{q}_{\mathrm{eq} 1}+\mathrm{C}_{\text {eq1 }} \cdot \mathrm{V}_{\text {init }}
$$

Eq. 4 can be rearranged as follows,

$$
-\left(\frac{V_{\text {init }}}{X_{\text {init }}}\right)=\frac{\left(q_{\text {eq1 }}-q_{\text {init }}\right)}{\left(C_{\text {eq } 1}-C_{\text {init }}\right)}
$$

In the same way, Eq. 5 can be rearranged for $\mathrm{n}^{\text {th }}$ stage as follows,

$$
-\left(\frac{\mathrm{V}_{\text {init }}}{\mathrm{X}_{\text {init }}}\right)=\frac{\left(\mathrm{q}_{\mathrm{eqn}}-\mathrm{q}_{\text {init }}\right)}{\left(\mathrm{C}_{\mathrm{eqn}}-\mathrm{C}_{\mathrm{eq}(\mathrm{n}-1)}\right)}
$$

The adsorbed BR46 mass per gram of AgNPs at the entrance of each reactor ( $\left.\mathrm{q}_{\text {init }}\right)$ is equal to zero. The operating lines, provided from Eq. (5) and Eq. (6), passing through $\left(\mathrm{q}_{\mathrm{init}}, \mathrm{C}_{\mathrm{init}}\right)$ and $\left(\mathrm{q}_{\mathrm{eq} 1}, \mathrm{C}_{\mathrm{eq} 1}\right)$ for the $1^{\text {st }}$ stage and $\left(\mathrm{q}_{\mathrm{init}}, \mathrm{C}_{\mathrm{eq}(\mathrm{n}-1)}\right)$ and $\left(\mathrm{q}_{\mathrm{eqn}}, \mathrm{C}_{\mathrm{eqn}}\right)$ for the $\mathrm{n}^{\text {th }}$ stage, respectively. If the amount of AgNPs used in each stage is equal, the operating lines, each slope is $-V_{\text {init }} / \mathrm{X}_{\text {init }}$, are parallel [16].

For BR46 adsorption onto AgNPs, the equilibrium curve plotted by the experimental equilibrium data $\left(\mathrm{C}_{\mathrm{eq}}, \mathrm{q}_{\mathrm{eq}}\right)$ along with the operating lines whose slopes were $1.0\left(-\left(\mathrm{V}_{\text {init }} / \mathrm{X}_{\text {init }}\right)=-(1 \mathrm{~L} / 1 \mathrm{~g})=-1\right)$ for four stages were given in Figure 10. From Figure 10, the unadsorbed BR46 concentrations at the $1^{\text {th }}, 2^{\text {th }}, 3^{\text {th }}$, and $4^{\text {th }}$ stages were determined as $376,256,138$, and $38 \mathrm{mg} / \mathrm{L}$ for initial BR46 concentration of $501.17 \mathrm{mg} / \mathrm{L}$, respectively.

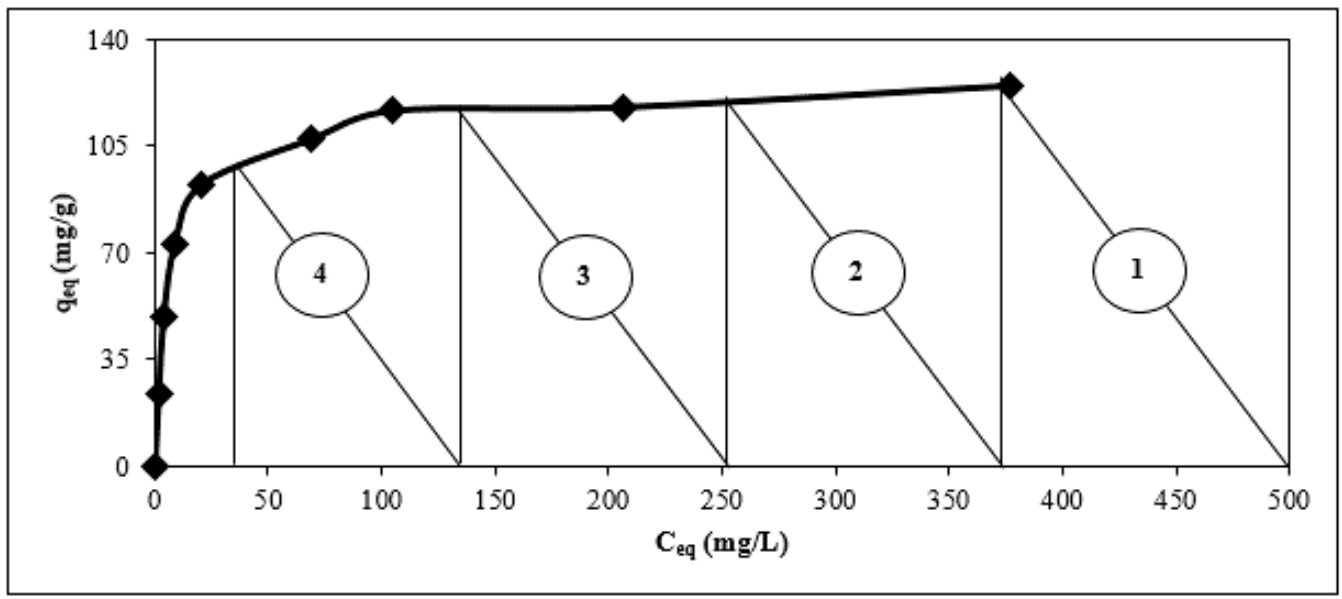

Figure 10. The equilibrium curve with the operating lines (each slope: $-V_{\text {init }} / X_{\text {init }}=-1$ ) for four staged batch stirred reactor in series 
The multistage adsorption system can be also described mathematically by use of Langmuir isotherm model to forecast the unadsorbed dye concentration for each stage. Substituting the Langmuir equation for $\mathrm{q}_{\mathrm{eq} 1}\left[=\frac{\mathrm{q}_{\mathrm{m}} \cdot \mathrm{b}_{\mathrm{L}} \cdot \mathrm{C}_{\mathrm{eq} 1}}{1+\mathrm{b}_{\mathrm{L}} \cdot \mathrm{C}_{\mathrm{eq} 1}}\right]$ and $\mathrm{q}_{\mathrm{eqn}}$, in Eqs. (7) and (8) gives:

$$
\begin{gathered}
y=-\left(\frac{V_{\text {init }}}{x_{\text {init }}}\right)=\frac{\left(q_{m} \cdot b_{L} \cdot C_{e q 1}\right)}{\left[\left(1+b_{L} \cdot C_{e q 1}\right) \cdot\left(C_{e q 1}-C_{\text {init }}\right)\right]} \\
y=-\left(\frac{V_{\text {init }}}{x_{\text {init }}}\right)=\frac{\left(q_{m} \cdot b_{L} \cdot C_{\text {eqn }}\right)}{\left[\left(1+b_{L} \cdot C_{\text {eqn }}\right) \cdot\left(C_{\text {eq }}(n-1)-C_{\text {eqn }}\right)\right]}
\end{gathered}
$$

Rearranging Eqs. 7 and 8 give for stages $1^{\text {th }}$ and $\mathrm{n}^{\text {th }}$ :

$$
\begin{gathered}
b_{L} \cdot C_{e q 1}{ }^{2}+\left(1-b_{L} \cdot C_{i n i t}+q_{m} \cdot b_{L} \cdot y\right) C_{e q 1}-C_{i n i t}=0 \\
b_{L} \cdot C_{e q n}{ }^{2}+\left(1-b_{L} \cdot C_{e q(n-1)}+q_{m} \cdot b_{L} \cdot y\right) C_{e q n}-C_{e q(n-1)}=0
\end{gathered}
$$

The positive root calculated from analytical solution of Eqs. 9 and 10 gives the equilibrium dye concentration for $1^{\text {th }}$ and $\mathrm{n}^{\text {th }}\left(\mathrm{C}_{\text {eq } 1}, \mathrm{C}_{\text {eqn }}\right)$ stages, respectively.

At the optimum adsorption conditions, the experimental $\mathrm{q}_{\mathrm{m}}$ and $\mathrm{b}_{\mathrm{L}}$ values were used for obtaining $\mathrm{C}_{\mathrm{eq}}$ values in the output of each stage from Eqs. 9 and 10. The unadsorbed BR 46 concentrations at the end of the $1^{\text {th }}, 2^{\text {th }}, 3^{\text {th }}$, and $4^{\text {th }}$ stages were determined as $376.92,253.74,133.39$ and $30.15 \mathrm{mg} / \mathrm{L}$, respectively. As a conclusion, there is good consistency between the equilibrium BR 46 concentrations determined by the experimental equilibrium data-operating line method and calculated with the aid of Langmuir isotherm model constants.

It was clearly understood from the unadsorbed BR 46 concentrations that the required purification could not be provided by a single stage according to the discharge standards given by Water Pollution Control Regulation of T.R. Environment and Urbanization Ministry (Table 6); but it was observed that the unadsorbed BR 46 concentration could be reduced below the discharge limit values in four-staged adsorption system.

Table 6. Discharge limit values according to Water Pollution Control Regulation of T.R. Environment and Urbanization Ministry

\begin{tabular}{cccc}
\hline Parameter & Unit & Sample for 2 hours & Sample for 24 hours \\
\hline Chemical oxygen demand $(\mathrm{COD})$ & $(\mathrm{mg} / \mathrm{L})$ & 350 & 240 \\
Nitrogen of Ammonium $\left(\mathrm{NH}_{4}-\mathrm{N}\right)$ & $(\mathrm{mg} / \mathrm{L})$ & 5 & - \\
Free chlorine & $(\mathrm{mg} / \mathrm{L})$ & 0.3 & - \\
Total chrome & $(\mathrm{mg} / \mathrm{L})$ & 2 & - \\
Sulfur $\left(\mathrm{S}^{-2}\right)$ & $(\mathrm{mg} / \mathrm{L})$ & 0.1 & - \\
Sulphite & $(\mathrm{mg} / \mathrm{L})$ & 1 & - \\
Oil and grease & $(\mathrm{mg} / \mathrm{L})$ & 10 & $6-9$ \\
pH & - & $6-9$ & 260 \\
Color & $(\mathrm{Pt}-\mathrm{Co})$ & 280 & 48 \\
\hline
\end{tabular}

\section{CONCLUSION}

AgNPs were biosynthesized using Cyprus acacia (Acacia cyanophylla) leaf extract and they were characterized by DLS, FT-IR, SEM, EDX, XRD. The biosynthesized AgNPs were used as adsorbents in the single stage adsorption of BR46 onto AgNPs in the batch system and the optimum conditions were determined as follows: initial $\mathrm{pH}$ of 7.0 , initial dye concentration of $200 \mathrm{mg} / \mathrm{L}$, temperature of 
$35{ }^{\circ} \mathrm{C}$, and adsorbent concentration of $1.0 \mathrm{~g} / \mathrm{L}$. Weber-Morris model results showed that only intraparticle diffusion was effective in the removal. The BR46 adsorption kinetics was in the best agreement with the pseudo second order model. Thermodynamic studies stated that the studied adsorption process was exothermic, induced, and decreasing in randomness of adsorbed species. The BR46 adsorption equilibrium was defined by Langmuir isotherm model. The maximum monolayer coverage capacity of AgNPs was determined as $126.48 \mathrm{mg} / \mathrm{g}\left(\mathrm{R}^{2}=0.994\right.$, Err $\left.=3.74\right)$ at $35^{\circ} \mathrm{C}$, which was the optimum temperature value and the calculated maximum monolayer coverage capacity of AgNPs confirmed that the biosynthesized AgNPs could be used effectively for BR46 adsorption in comparison to the other nanoparticles used for different dyes. In addition, the multistage adsorption of BR46 onto AgNPs was studied; it was observed that the desired purification could be achieved by four staged adsorption system.

\section{NOMENCLATURE}

1/n a constant of Freundlich isotherm model related to adsorption intensity

$b_{\mathrm{L}} \quad$ a constant of Langmuir isotherm model $(\mathrm{L} / \mathrm{mg})$

$\mathrm{C}_{\mathrm{eq}} \quad$ concentration of residual BR46 at equilibrium $(\mathrm{mg} / \mathrm{L})$

$\mathrm{C}_{\mathrm{eqn}} \quad$ concentration of residual BR46 at equilibrium for $\mathrm{n}^{\text {th }}$ stage $(\mathrm{mg} / \mathrm{L})$

$\mathrm{C}_{\text {init }} \quad$ initial concentration of BR46 $(\mathrm{mg} / \mathrm{L})$

Err error value

$\mathrm{k}_{\mathrm{f}} \quad$ a rate constant of pseudo first order kinetic model $(1 / \mathrm{min})$

$\mathrm{K}_{\mathrm{fr}} \quad$ a constant of Freundlich isotherm model $\left.(\mathrm{mg} / \mathrm{g}) /(\mathrm{L} / \mathrm{mg}) 1 / \mathrm{n}\right)$

$\mathrm{K}_{\text {in }} \quad$ Weber-Morris model constant related to intraparticle diffusion (mg/g.min $\left.{ }^{0.5}\right)$

$\mathrm{k}_{\mathrm{s}} \quad$ a rate constant of pseudo second order kinetic model $(\mathrm{g} /(\mathrm{mg} \min ))$

oop out of plane

$\mathrm{q}_{\mathrm{eq}} \quad$ adsorbed mass of BR46 per gram of AgNPs at equilibrium (mg/g)

qeq,call adsorbed mass of BR46 per gram of AgNPs calculated from pseudo first order kinetic model (mg/g)

qeq,cal2 adsorbed mass of BR46 per gram of AgNPs calculated from pseudo second order kinetic model (mg/g)

qeq,ex experimental adsorbed mass of BR46 per gram of AgNPs at equilibrium $(\mathrm{mg} / \mathrm{g})$

qeqn adsorbed mass of BR46 per gram of AgNPs at equilibrium for $\mathrm{n}^{\text {th }}$ stage $(\mathrm{mg} / \mathrm{g})$

$\mathrm{q}_{\mathrm{m}} \quad$ maximum monolayer coverage capacity of AgNPs obtained from Langmuir isotherm model $(\mathrm{mg} / \mathrm{g})$

qo adsorbed mass of BR46 per gram of AgNPs at the beginning in each reactor $(\mathrm{mg} / \mathrm{g})$

$\mathrm{T} \quad$ temperature $\left({ }^{\circ} \mathrm{C}, \mathrm{K}\right)$

$\mathrm{t} \quad$ time (min)

$\mathrm{V}_{\text {init }} \quad$ adsorption solution volume (L)

$\mathrm{X}_{\text {init }} \quad$ AgNPs concentration $(\mathrm{g} / \mathrm{L})$

$\Delta \mathrm{G} \quad$ change of Gibb's free energy $(\mathrm{J} / \mathrm{mole})$

$\Delta \mathrm{H} \quad$ change of enthalpy $(\mathrm{J} / \mathrm{mole})$

$\Delta \mathrm{S} \quad$ change of entropy $(\mathrm{J} / \mathrm{mole} . \mathrm{K})$

\section{REFERENCES}

[1] Ghaedi M, Sadeghian B, Pebdani AA, Sahraei R, Daneshfar A and Duran C. Kinetics, thermodynamics and equilibrium evaluation of direct yellow 12 removal by adsorption onto silver nanoparticles loaded activated carbon. Chem Eng J 2012; 187: 133-141.

[2] Haiss W, Thanh NT, Aveyard J and Fernig DG. Determination of size and concentration of gold nanoparticles from UV-vis spectra. Anal Chem 2007; 79(11): 4215-4221. 
Taşkıran et al. /Anadolu Univ. J. of Sci. and Technology A-Appl. Sci. and Eng. 18 (3) - 2017

[3] Umer A, Naveed S, Ramzan N and Rafique MS. Selection of a suitable method for the synthesis of copper nanoparticles. Nano 2012; 7(05): 1230005.

[4] Veerasamy R, Xin TZ, Gunasagaran S, Xiang TFW, Yang EFC. Jeyakumar N and Dhanaraj SA. Biosynthesis of silver nanoparticles using mangosteen leaf extract and evaluation of their antimicrobial activities. J Saudi Chem Soc 2011; 15(2): 113-120.

[5] Awwad AM, Salem NM, and Abdeen AO. Green synthesis of silver nanoparticles using carob leaf extract and its antibacterial activity. IJIC 2013; 4(1): 1-6.

[6] Muthukumaran U, Govindarajan M, Rajeswary M and Hoti SL. Synthesis and characterization of silver nanoparticles using Gmelina asiatica leaf extract against filariasis, dengue, and malaria vector mosquitoes. Parasitol Res 2015; 114(5): 1817-1827.

[7] Mishra PM, Sahoo SK, Naik GK and Parida K. Biomimetic synthesis, characterization and mechanism of formation of stable silver nanoparticles using Averrhoa carambola L. leaf extract. Mater Lett 2015; 160: 566-571.

[8] Sathyavathi R, Krishna MB, Rao SV, Saritha R and Rao DN. Biosynthesis of silver nanoparticles using Coriandrum sativum leaf extract and their application in nonlinear optics. Adv Sci Lett 2010; 3(2): 138-143.

[9] Aitenneite H, Abboud Y, Tanane O, Solhy A, Sebti S and Bouari AE. Rapid and green microwaveassisted synthesis of silver nanoparticles using aqueous Phoenix Dactylifera L. (date palm) leaf extract and their catalytic activity for 4-Nitrophenol reduction. J Mater Environ Sci 2016; 7(7): 2335-2339.

[10] Kumar DA, Palanichamy V and Roopan SM. Green synthesis of silver nanoparticles using Alternanthera dentata leaf extract at room temperature and their antimicrobial activity. Spectrochim Acta A Mol Biomol Spectrosc 2014; 127: 168-171.

[11] Prakash P, Gnanaprakasam P, Emmanuel R, Arokiyaraj S and Saravanan M. Green synthesis of silver nanoparticles from leaf extract of Mimusops elengi, Linn. for enhanced antibacterial activity against multi drug resistant clinical isolates. Colloids Surf B Biointerfaces 2013; 108: 255-259.

[12] Khalil MM, Ismail EH, El-Baghdady $\mathrm{KZ}$ and Mohamed D. Green synthesis of silver nanoparticles using olive leaf extract and its antibacterial activity. Arab J Chem 2014; 7(6): 11311139.

[13] Lee JH, Hwang KS, Jang SP, Lee BH, Kim JH, Choi SU and Choi CJ. Effective viscosities and thermal conductivities of aqueous nanofluids containing low volume concentrations of $\mathrm{Al}_{2} \mathrm{O}_{3}$ nanoparticles. Int J Heat Mass Transf 2008; 51(11): 2651-2656.

[14] Yola ML, Eren T, Atar N and Wang S. Adsorptive and photocatalytic removal of reactive dyes by silver nanoparticle-colemanite ore waste. Chem Eng J 2014; 242: 333-340.

[15] Salem MA, Elsharkawy RG and Hablas MF. Adsorption of brilliant green dye by polyaniline/silver nanocomposite: Kinetic, equilibrium, and thermodynamic studies. Eur Polym $\mathbf{J}$ 2016; 75: 577-590.

[16] Özer A, Özer D, Dursun G and Bulak S. Cadmium (II) adsorption on Cladophora crispata in batch stirred reactors in series. Waste Manage 1999; 19(3): 233-240. 